Murray J. Girotti MD FRCSC, Giuseppe Pagliarello MD FRCSC, Thomas R. Todd MD FRCSC, Wilfred Demajo MD FRCPC, John Cain MD FRCPC, Paul Walker MD FRCsC, Alec Patterson MD FrCsC

\title{
Physician-accompanied transport of surgical intensive care patients
}

During a one-year period, 107 critically ill adult patients were transferred by a physician-accompanied transport system ( $P_{A} T$ TS). Most patiens required both tracheal inubation $(82$ per cent) and mechanical ventilation (71 per cent), while contimuous vasopressor support was required in 27 per cent of transfers. Patiends were classified as either potential organ donors $(n=$ $21)$ or nondonor patients $(n=86)$. Nondonor patients had a mean time of patient transfer documented from the initial telephone contact to final arrival of the patient in the ICU of 345 \pm 221 min (range $65-1350$ min); the mean time the patients were out-of-hospital was $73 \pm 58 \mathrm{~min}$ (range 5-330 min); the average distance travelied by the patient and PATS was $342 \pm$ $692 \mathrm{~km}$ (range $1-4000 \mathrm{~km}$ ). Ultimate nonsurvivors of $\mathrm{KCU}$ admission ( 36 per cent) had shorter out-of-hospital times, shorter travel distances, and increased interventional support, as assessed by the Therapeutic Intervention Scoring System applied over the telephone and prior to departure at the referring hospital. Significant interventions were undertaken by PATS in 23 per cent of the nondonor patients prior to departure. During the transport process, there was at least a seven per cent morbidity (arrhythmia, hypotension, and vehicular difficulties) and a 0.9 mortality rate. We conclude that PATS offered significant advantages to this patient population through its ability to maintain acceptable morbidity and mortality rates while transferring patients over long distances and for prolonged periods of time.

\section{Key words}

TRANSPORT, PATIENT: ambulance, air-ambulance, physician-accompanied; INTENSIVE CARE UNIT: patient transport, outcome

From The Surgical Intensive Care Research Group, Department of Surgery, Toronto General Hospital, Toronto, Ontario.

Address correspondence to: Dr. M.J. Girotti, EN 9-234, Toronto General Hospital, 200 Elizabeth Street, Toronto, Ontario, M5G 2C4
Within the tiered health care system of North America, patients requiring urgent and sophisticated tertiary and sometimes quatemary intensive care are often encountered in far less technologically advanced and remote hospitals. Rapid access to the modern techniques and skilled personnel available in advanced intensive care facilities is a prerequisite within this layered health care system. Without these treatements, outcome from profound illness would be in doubt. ${ }^{1-3}$ To provide the needed access to these facilities, patient transport systems of various types have evolved. These have included paramedical air transport teams based on the Viet Nam war experience, advanced life support ground ambulances and hospitalbased critical care transport teams. Transportation of critically ill patients over large distances and for prolonged periods of time has become an everyday occurrence. While removed from the referring emergency departments and intensive care units, these patients are often placed in an unmonitored and resource-poor environment. The potential risk for deterioration in clinical status during this process is significant.

The impact of efficient medical evacuation systems on two patient populations has been prospectively analyzed and a significant change in mortality statistics has been demonstrated through medical evacuation systems. Neonatal intensive care units and the availability of neonatal medical transport teams have been shown to reduce significantly mortality rates in low birth weight infants suffering from congenital heart disease and infant respiratory distress syndrome. ${ }^{4-6}$ Aeromedical transport teams for the management of major blunt trauma patients resulted in a significant decrease in projected mortality for these patients in a multicentre trial ${ }^{7}$ There are few publications examining the transport of critically ill adults between hospitals.

In 1953, the Toronto General Hospital organized and established one of the first critical care facilities in the world. ${ }^{8}$ Since that time a physician-accompanied transport system (PATS) for critically ill adults has been operational. This system has allowed the Toronto General Hospital to extend its intensive care personnel and facilities far from its regional hospital base. PATS has evolved in an effort to provide a level of patient care as close as possible to that received at the Toronto General Hospital. 
This study was designed to prospectively review our experience with PATS for adult Surgical Intensive Care Unit patients over a one-year period. The study was organized to assess not only the type of patients that were transferred but also the morbidity and mortality of this process.

\section{Methods}

The Surgical Intensive Care Unit (SICU) of the Toronto General Hospital (TGH) is a 16-bed unit within a 1000 . bed institution. The SICU attending staff members (four surgeons and two anaesthetists) are directly responsible for the ongoing clinical care in the SICU as well as for the supervison of PATS.

Under most circumstances, referring physicians requesting transfer of critically ill patients contact the SICU attending physician on call. The accepting SICU physician obtains pertinent clinical data from the referring doctor and determines the urgency and optimum method of transfer. The SICU attending physician then activates PATS, which is composed of either a senior year (year 3 , 4 , or 5) surgical or anaesthesia resident together with a qualified respiratory therapist. All resident staff members are skilled in all facets of airway and haemodynamic stabilization. The physicians and respiratory therapists bave receved fromal instruction in managing potential problems in the evacuation of critically ill patients. The SICU has not employed intensive care unit nurses to transfer any of these patients. The type of vehicle for transfer is determined after discussion with either the Central Ambulance Communication Centre for Metropolitan Toronto, or through a special hospital-run private air evacuation service. This decision is based on availability of vehicles and other support personnel, weather conditions, and distances to be travelled. The costs for all Ontario residents, regardless of where the transfer originated from, were paid for by the provincial health care scheme (Ontario Health Insurance Program). Transfer costs for non-Ontario residents were paid for by their respective provincial health care plans.

PATS and the patient are transported either by regular gound ambulance or by air ambulances of several designs (fixed wing, helicopter, and jet). PATS normally brings its own resuscitation supplies including standard cardiopulmonary resuscitative medications, intravenous solutions and intravenous tubing including assorted catheters for all types of yenous cannulation, defibrillator, electrocardiographic (ECG) monitor, suction device, ventilator and, on occasion, a bronchoscope as would be required for the individual patient. Patients who required ventilation, with or without PEEP, were managed with either manual ventilation or preferably with a portable Monaghan ventilator driven by a supply of exchangeable $E$ size pressurized oxygen cylinders. Continuous intravenous medications, usually vasopressors, were administered with a battery-operated pump (Imed Corporation, San Diego, CA, model \#960, battery time three hours at full charge). Due to technical problems with continuous pressure monitoring (low battery half-life), patients with indwelling arterial catheters did not have the catheter connected to a pressure transducer unless they were expected to have an out-of-hospital time of under 30 minutes.

Prior to departure from the referring centre, PATS ensures patient stabilization for transfer by whatever means necessary (e.g. , intubation, ventilator adjustments, establishment of intravenous routes, etc.). Communications and overal medical supervision are maintained with PATS by the altending SICU physician at the referring hospital and in transport by cither direct telephone contact or by an onboard ambulance two-way radio system linked by telephone to the SICU.

All patients transferred by PATS from February 1, 1986 to January 31,1987 were analysed. Pertinent clinical and transport data were recorded on a specially designed transport form. Standard vitals signs were recorded on the patients from the moment of arrival at the referring hospital until return to the SICU on a frequent basis (at least every ten minutes). All current blood work was noted on the transfer form. Pertinent radiographs were transported with the patient. When available, cross-matched blood was transported with the patient and given en route if deemed necessary by the PATS physician. For the purpose of this study, morbidity was defined as: any change in cardiac rhythm which was different from the patient's rhythm in the referring hospital; any episode of hypotension (systolic blood pressure $<90 \mathrm{mmHg}$ ); sudden changes in ventilation pressures; increased and prolonged distress of the patient during transport; any change in the transfer process which resulted in a potential delay in patient transfer that was otherwise unexpected.

The interventions employed to support and monitor the patients during transfer were measured by a simple modification of the therapeutic intervention scoring system (TISS) and recorded on the transport form. ${ }^{3,9}$ TISS was determined at first telephone contact (TISS-TEL) and prior to departure (TISS-DEP) from the referring hospital. Standard TISS values were recorded on the first day of admission (TISS-1) to the SICU.

Time for the various aspects of the transfer, namely, start up (initial time of telphone contact to departure from the SICU), time to (SICU to referring hospital), pack up (time required to stabilize patient for transfer), time in (time from referring hospital to the SICU), total time (overall time for the transter process), and total distances were noted. A time/distance ratio $(\mathrm{min} / \mathrm{km})$ was calculated for each transport based on the total time for transfer 
TABLE 1 Transfer diagnosis and outcome from SICU admission

\begin{tabular}{llll}
\hline & \multicolumn{2}{l}{ Outcome } & \\
\cline { 2 - 4 } Diagnosis & Overall & Survivors & Nonsurvivors \\
\hline Scpsis & 24 & 14 & 10 \\
Respiratory failure & 17 & 12 & 5 \\
Trauma & 6 & 6 & 0 \\
GI bleed & 19 & 12 & 7 \\
Post-aneurysmectomy & & & \\
$\quad$ (emergency) & 9 & 4 & 5 \\
Miscellaneous & 11 & 7 & 4 \\
Organ donor* & 21 & 0 & 21 \\
\hline
\end{tabular}

FDetermined before transfer.

divided by the total distance for each trip. Cardiopulmonary and laboratory data from the referring hospital were recorced when available.

All data are reported as the mean \pm standard deviation Two sample comparisons were done using an unpaited $t$ test. Group means were compared by the KruskalWallis rnodification of the analysis of variance. ${ }^{10}$ Associations between variables were evaluated by a Pearson $\chi^{2}$ and a Likelihood Ratio $\chi^{2}$ statistic." "The alpha error level for statistical significance was selected at 0.05 .

\section{Results}

Over the one-year study period, 107 patients were transferred by PATS. The average age of the transferred patients was $52 \pm 18$ years (range $16-86$ years). Tracheal intubation was present in 82 per cent of all transfers. Assisted mechanical ventilation was employed in 71 per cent of all patients. Vasopressors were administered continuously in 27 per cent of all patients while 24 per cent needed both mechanical ventilation and vasopressors to maintain cardiopulmonary stability.

The major clinical conditions requiring transfer fell into seven broad categories: sepsis with multiple systems organ failure; pneumonia with acute respiratory failure; trauma; major gastrointestinal haemorthage - most often variceal in origin; multiple systems organ failure; post-emergency abdominal aortic aneurysmectomy; brain death - possible multiple organ donation; and miscellaneous (drug overdose, acute airway obstruction etc). The overall number and survival of these patients is shown in Table I. Excluding the 21 possible organ donor patients, there was a 36 per cent mortality rate following SICU admission. In the nondonor patients, there was no correlation between survival and reason for transfer (Pearson $\chi^{2}=0.355$, Likelihood ratio $\chi^{2}=0.910$ ). The need for continuous vasopressor support during transport was not associated with a decreased survival following SICU admission (Pearson $\chi^{2}=0.420$, Likelihood ratio $\chi^{2}=$ 0.551 ).

The time for the various components of patient trans-
TABLE II Time and distance dată for all study patients

\begin{tabular}{|c|c|c|c|c|}
\hline & \multicolumn{3}{|l|}{ Mondonors } & \multirow{2}{*}{$\begin{array}{l}\text { Donors } \\
\text { Overall } \\
(n=2 l)\end{array}$} \\
\hline & $\begin{array}{l}\text { Survivors } \\
(n=55)\end{array}$ & $\begin{array}{l}\text { Nonsurwivers } \\
{[n=3 !)}\end{array}$ & $\begin{array}{l}\text { Overall } \\
(n=86)\end{array}$ & \\
\hline \multicolumn{5}{|c|}{ Time factors (min)* } \\
\hline Star up & $144 \pm 195$ & $114 \pm 126$ & $133 \pm 174$ & $126 \pm 231$ \\
\hline Time to & $97 \pm 102$ & $49 \pm 32 \dagger$ & $79 \pm 87$ & $55 \pm 107$ \\
\hline Pack-up & $70 \pm 45$ & $71 \pm 47$ & $70 \pm 45$ & $45 \pm 20$ \\
\hline Time in & $85 \pm 64$ & $52 \pm 35 \dagger$ & $73 \pm 58$ & $55 \pm 99$ \\
\hline Totsl lime & $377 \pm 240$ & $288=172 \dagger$ & $345 \pm 221$ & $286 \pm 356$ \\
\hline \multicolumn{5}{|c|}{ Distance factors } \\
\hline Total $(\mathrm{km})$ & $457 \pm 836$ & $14 !=180 \dagger$ & $342 \pm 692$ & $519 \pm 1738$ \\
\hline $\begin{array}{l}\text { Time/distance } \\
\text { ratio } \\
\left(\min \cdot \mathrm{km}^{-1}\right)\end{array}$ & $1.1 \pm 1.3$ & $2.4=3.7$ & $1.6 \pm 2.5$ & $1.6=0.9$ \\
\hline
\end{tabular}

* See text for time definitions.

$t_{p}<0.05$ survivors compared to nonsurvivors in the nondonar group.

port and distance of transport for the nondonor and donor populations are shown in Table II. Within the nondonor group a further breakdown of these characteristics is shown between survivors and nonsurvivors. The average total time for transfer regardless of diagnosis was well over five hours (333 $\pm 254 \mathrm{~min}$, range $65-1350 \mathrm{~min}, \mathrm{n}=$ 107). Significantly longer times for the survivors were observed in the time to and from the referring centre, as well as total time for transfer. This was due to the markedly longer distances travelied by the survivors. Stabilization times at the referring hospital (i.e. , pack up) were not different when survivors were compared to nonsurvivors. The single largest time component in the overall transfer process was the start up time (initial contast to departure from SICU).

There was a single transport death during the study period. An elderly patient had an attempted emergency resection of a slowly leaking abdominal aortic aneurysm associated with a retroperitoneal haematoma at a referring hospital $120 \mathrm{~km}$ from TGH. Due to significant technical difficultics, this could not be done and the operating surgeon decided to evacuate the patient for definitive vascular surgical management. The patient was transferred by PATS. Approximately $5 \mathrm{~km}$ from the TGH. SICU, the patient suddenly developed profound hypotension secondary to the complete rupture of the aneurysm. The patient was taken directly to the operating room and unfortunately suffered a major intraoperative myocardial infarction from which he could not be resuscitated. Three other patients developed new arrhythmias (two - supraventricular tachycardia, one - excessive premature ven. tricular contractions) in transport which successfully responsed to pharmacological management. There were no other significant clinical events in the transfer process 


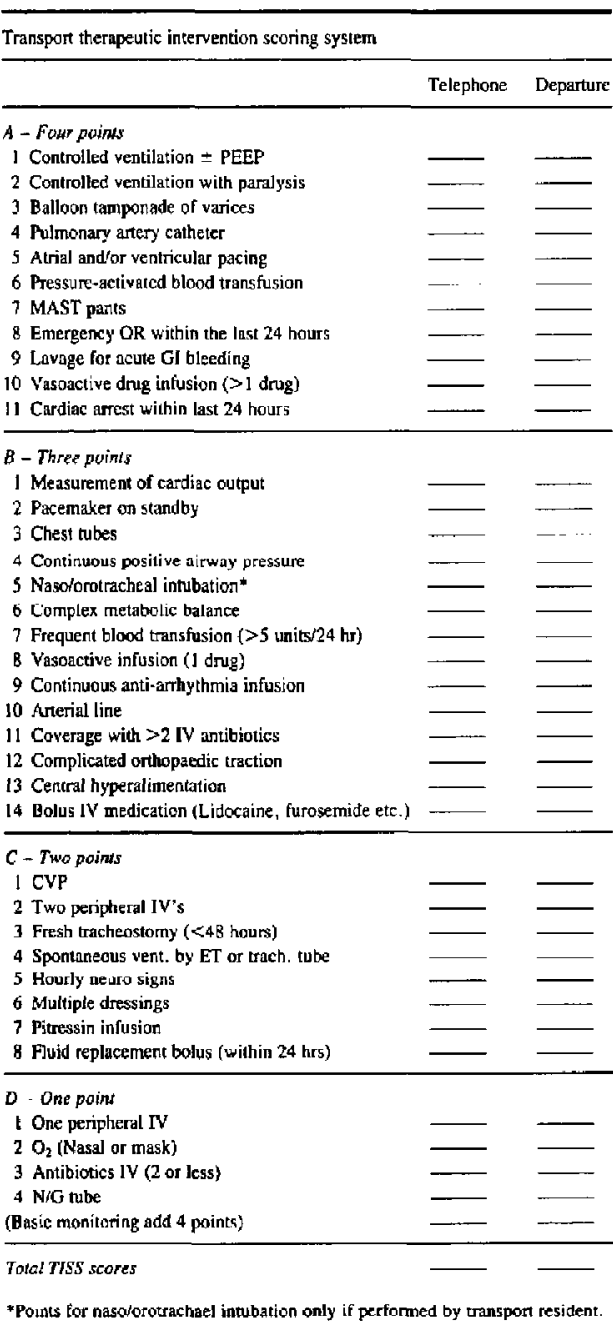

FlGURE Modified TISS scoring shect uscd to record the therapeutic interventions necessary prior to or during transport.

once the patient had been stabilized by PATS at the referring hospital. There were six separate instances where a major change in the evacuation process occurred as a result of inclement weather (snow or rain storm causing change from air to land vehicle) or technical failure of the transport vehicle (flat tire in ground vehicle).

Land ambulance was used by PATS to evacuate 48 patients ( 56 per cent), helicopter for 19 patients (22 per cent), fixed wing for 13 patients ( 15 per cent), and jet for six patients ( 7 per cent). The time/distance ratios for the method of evacuation were: land $2.5 \pm 3.1 \mathrm{~min} \cdot \mathrm{km}^{-1}$; helicopter $0.6 \pm 0.3 \mathrm{~min} \cdot \mathrm{km}^{-1}$; fixed wing $0.5 \pm 0.3$ $\min \cdot \mathrm{km}^{-1}$; and jet $0.2 \pm 0.1 \mathrm{~min} \cdot \mathrm{km}^{-1}$. The vehicle used for transter significantly affected the time/distance ratio (land $>$ air), but this did not correlate to overall SICU survival (Pearson $\chi^{2}=0.344$ and Likelihood ratio $x^{2}=0.322$ ).

The analysis of interventions employed in the transport process as assessed by TISS-TEL, TISS-DEP, and TISS-1 is displayed in Table III. Comparison of donors versus nondonors reveals statistically significant higher values of both TISS-TEL and TISS-DEP in the donor population. This reflected the fact that the majority ( 75 per cent) of possible organ donor patients were transferred from other tertiary care institutions where increased interventions would naturally be anticipated. Within the nondonor group, survivors and nonsurvivors of SICU admission were further analyzed. The non survivors had higher TISS-TEL, TISS-DEPT, and TISS-1 when compared to the survivors of SICU admission. There were $20 / 86$ patients ( 23 per cent) in the nondonor group who had an increase of greater than 3 TISS points when TISS-TEL was compared to TISS-DEP although there were no statistical differences between TISS-TEL and TISS-DEP when survivors or nonsurvivors were compared within each of these individual groups. Not surprisingly, higher TISS-TEL, TISS-DEP, and TISS-1 were associated with increased mortality rates (Pearson $x^{2}-0.028,0.023$, 0.001 ; Likelihood Ratio $\chi^{2}=0.022,0.021,0.0001$ respectively).

\section{Discussion}

This study of a physician-accompanied transport system for seriously ill adult surgical patients (overall mortality 34 per cent) leads us to conclude that prolonged and longdistance patient transfers can be accomplished safely. The results recorded herein suggest that the method of evacuation, referring diagnosis, and total time for transfer

TABLE IIt Assessment of therapeutic interyentions for all patients when compared by status as a donor or nondonor patient

\begin{tabular}{|c|c|c|c|c|}
\hline & \multicolumn{3}{|l|}{ Nondonor } & \multirow[b]{2}{*}{$\begin{array}{l}\text { Donor } \\
\text { overall } \\
(n=21)\end{array}$} \\
\hline & $\begin{array}{l}\text { Sunivors } \\
(n=55)\end{array}$ & $\begin{array}{l}\text { Non- } \\
\text { surwivors } \\
(n=31)\end{array}$ & $\begin{array}{l}\text { Overall } \\
(n=86)\end{array}$ & \\
\hline TISS-TEL & $15.4 \pm 6.7$ & $20.5=6.8^{*}$ & $17.3 \pm 7.1$ & $22.2 \pm 6.5 \dagger$ \\
\hline TISS-DEP & $15.8 \pm 7.6$ & $2 t .7 \pm 7.1^{*}$ & $17.9 \pm 7.4$ & $22.7 \pm 6.0 \dagger$ \\
\hline TrSS-1 & $27.6 \pm 10.5$ & $40.3 \pm 10.8^{*}$ & $32.3 \pm 12.2$ & - \\
\hline
\end{tabular}

${ }^{*} p<0.05$ survivors compared to nonsurvivors. tp $<0.05$ donors vs nondonors. 
were not associated with significant clinical events during transfer. It is no surprise that the evacuation mode correlated directly to the time/distance ratio when aircraft were compared to land vehicles. The average time for SICU patient transfer is over five hours with at least one hour of that time spent with the patient and PATS out of a hospital. Despite what might appear as an adequate stabilization time followed by a relatively short "at risk" period, there was a ten per cent morbidity in the transport process. Arrhythmias and vehicle/weather problems accounted for all of these incidents. One patient died during the transport process.

The application of a well-described and statistically validated interventional analysis system (TISS) provided interesting data regarding both interventions during transfer and eventual SICU survival. TISS allows for simple recording of the necessary therapeutic interventions for patient transfer which cannot be addressed by any other systcm. Although the overall increase in TISS-DEP compared to TISS-TEL was not statistically significant, almost one-quarter of the non donor patients recorded an increase of greater than three points (TISS-DEP) compared to TISS-TEL). Our experiences with TISS in over 1200 SICU patients leads us to believe that this represented a significant interventional change initiated by PATS. ${ }^{1,12}$ Predictably, the higher the TISS-TEL and TISS-DEP valucs the greater the likelihood of death during SICU admission. ${ }^{1}$

Physician-accompanied transport systems bave been previously reported. ${ }^{4-7,13-16}$ These reviews have been few in number and invariably have been retrospective in nature. Although these studies report sizable numbers of patients, they are mostly concerned with acute trauma or paediatric patients. The most recent report from Stanford Medical Center (SMC) retrospectively reviewed over 200 PATS transfers over a four-year period ${ }^{13}$ Despite much shorter overall distances travelled (260 vs $340 \mathrm{~km}$ ), the total transport times were close to our documented times. Comparison of these two unique patient populations, despite similar overall mortality rates ( 28 per cent vs 34 per cent), reveals interesting differences. The main reasons for evacuation to SMC were cardiac-related diagnoses (arrhythmias, acute infarction, and cardiogenic failure/shock). This accounted for very few transfers to the TGH-SICU. Over 70 per cent of the TGH-SICU population required mechanical ventilation. This is compared to only 36 per cent of the SMC patient population. Shock was present in 24 per cent of the TGH-SICU patients as comparcd to 14 per cent of the SMC patients. The SMC patients required more pharmacological agents due to the arrhythmia-related problems.

Several criticisms could be directed at this study. Firstly, a randomized comparative evaluation of PATS to other transport systems available such as paramedical air transports or non-physician-accompanied transports was not done. Logistically, this would have been very difficult to accomplish. Such a comparative study could have raised ethical considerations in the transfer of many patients in clinical shock whom we felt shoud be attended to by a physician. Secondly, the study did not address the key issue of resource use and dollar cost of PATS and its impact on TGH. Currently, the hospital's financial costing system and the provincial health care cost data for out-of-hospital transfers are not readily available for independent review. This problem has been partially examined by Thomas $e t a l$. in reviewing the economic impact of large numbers of air transported critically ill patients to an American tertiary care hospital. ${ }^{17}$ These authors concluded that the costs incurred by the receiving hospital were almost prohibitive and were significantly underestimated when the receiving hospital was reimbursed on a diagnosis-related group basis for these airevacuated patients. Finally, the actual incidence of morbidity as documented in this study was limited solely to arrhythmias and hypotension as noted on standard vital sign assessment and ECG recording. Admittedly, the use of more sophisticated equipment in these critically ill patients such as end-tidal carbon dioxide tension and continuous arterial oxygen saturation measurements would have allowed us to define morbidity to a greater degree. However, these technologies remain expensive and at the time of the initiation of this study there were no proven, reliable products of this nature which were available for use in prolonged out-of-hospital patient transfers.

Within the limitations of this study, we believe we can conclude that transfer of critically ill SICU patients can be done safely through the use of PATS. Changes in therapy and physiological support can be carried out at the referring hospital by experienced, and continuously supervised critical care transport teams and thus minimize the risk of significant clinical events in the evacuation of the se patients. We feel that PATS offered significant advantages to these scriously ill patients. We believe that future studies should continue to address the cost and the morbidity of the transfer process through the use of more sophisticated technology such as better monitors for out-of-hospital use and more detailed information regarding continuous cardiopulmonary status of individual patients.

\section{Acknowledgements}

The authors wish to thank Ms. Susanne Brown, Dawn Buske, Catherine Renwick, and Deborah Wilson for their efforts in the collection and collation of the data and preparation of the manuscript. 


\section{References}

1 Giroti MJ, Brown SJL. Factors predicting outcome from intensive care. A Canadian experience. Can Anaesth Soc I 1986; 33: 294-9.

2 Parno JR, Teres D. Lemeshow S, Brown RB. Hospital charges and long term survival of ICU and non-ICU paticnts. Crit Care Med 1982; 10: 569-72.

3 Cullen DJ, Ferraro LC, Briggs BA, Walter Pl, Gilbert J. Survival, hospitalization charges and followup results in critically ill patients. N Engl J Med 1976; 294: 982-7.

4 Thompson $T$, Reynolds $J$. The results of intensive care therapy for neonates. J Perinat Med 1977; 5: 59-75.

5 Lee K, Tieng PI, Eidetmas AI et al. Determinants of the neonatal mortality. Am J Dis Child 1976; 130: 842-5.

6 Ferrara A, Atakemt Y. Nconatal stabilization score: a quantitative method of auditing medical care in transports of new borns weight less than 1000 grams at birth. Med Care 1986; 24: 179-87.

7 Baxt WG Moody P, Cleveland HC et al. Hospital based rotorcraft aeromedical emergency care services and trauma mortality: a multicenter study. Ann Emerg Med 1985; 14: 859-64.

8 Bendixen $H$. History of intensive care. In: Manual of Surgical Therapeutics, Chap I. Philadelphia, W.B. Saunders, 1977; p. 3.

9 Cullen DJ, Civesta $J M$, Briggs BA, Ferraro LC. Therapeutic intervention scoring system: a method for quantitative comparison of patient carc. Crit Care Med 1975; 2: $57-66$

10 Godfrey $K$. Comparing the means of several groups. N Engl J Med 1985; 313: 1450-6.

11 Snedecor GW, Cochran WG. Statistical Methods, 7th Edition, Iowa, lowa State University Press 1980; p. 233-6.

12 Girotti MJ, Brown SJL. Reducing the cost of the ICU admission in Canada without diagnosis related or case mix groupings. Can Anaesth Soc J 1986; 33: 765-72.

13 Ehrenwerth J, Sorbo S, Hackel A. Transport of critically ill adults. Crit Care Med 1986; 14: 543-7.

14 Smith DF, Hackel A. Selection criteria for pedjatric critical care transport teams. Crit Care Med 1983; 11: 10-2.

15 Black RE, Mayer T, Walter ML et al. Air transport of pediatric emergency cases. N Engl J Med 1982; 307: 1465-7.

16 Harless $K W$, Morris AA, Cengiz $M$ et al. Civilian ground and air transport of adults with acute respiratory failure. JAMA 1978; 240: 361-5.

17 Thomes F, Lar.xen $K$, Clemmen TP, et al Impact of prospective payments on a tertiary care centre receiving a large number of critically ill patients by aeromedical transport. Crit Care Med 1986; 14: 227-30.

\section{Résumé}

Pour une période d'un an 107 patients adultes en état critique ont élé transférés avec un système de transport accompagné d'un médecin (PATS), La majorité des patients ont requis une intubation trachéale ( $\$ 2$ pour cent) et uhe ventilation mécanique (7I pener cent), alors qu' une perfusion continue de vasopresseurs était requise chez 27 pour cent des patients transférés, Les patients étaient classifiess soit en donneurs d"organes en puis. sance $(n=21)$ ou en non-donneurs $(n=86)$. Le temps moyen du transfert des potients non-donneurs documentés à partir du contact eêléphonique initial à l'arrivée du patient aux soins intensifs était de $345 \pm 221 \mathrm{~min}$ (écort $65-1350 \mathrm{~min}$ ). Le temps moyen où les patients étaient en dehors de l' hôpital était de $73 \pm$ 58 minutes (écart de 5-330 min). La distance moyenne parcourue par le patient érair de $342 \pm 692 \mathrm{~km}$ lecarr de $1-4000 \mathrm{~km}$ ). Les patients qui $n^{\prime}$ ont pas survécu à leur admission aux soins indensifs ( 36 pour cent) avaient une plus courte durée de séjour en dehors de l'hopital, ont parcouru une plus courte distance et ont nécessité des interventions de support tal qu'évalué par le Therapeutic Intervention Scoring System appliqué au téléphone et avant le départ de lhôpitat. Des interventions majeures étaient entreprises par le PATS chez 23 pour cent des patients non-donneurs avan le départ. Pendant le processus de sransport il y avait au moins sept pour cen de morbidite (arythmies, hypotension et difficultés de transport) et 0.9 pour cent de mortalité. On conclut que ie PATS offrait des avantages significatifs à ce groupe de paticrits par sa capacilé de maintenir un taux de mortalité et de morbidite acceptable iors $d^{\prime}$ un transfert des patients pour de longues distances et des. durÉes de tempts prolonge. 